\title{
Delayed presentation of acute scrotum: a rare age for torsion
}

\author{
Brandon Allen • Adam J. Ball • Anil Desai
}

Received: 4 February 2010/Accepted: 24 February 2010/Published online: 21 April 2010

(C) SIMI 2010

An active and otherwise healthy, 59-year-old male presented to a small, community emergency department (ED) on Christmas Eve with complaints of scrotal swelling and testicular pain following a round of golf. Upon arrival that afternoon to the ED and following assessment, a scrotal ultrasound revealed absence of blood flow to the left testicle, consistent with testicular torsion. Manual detorsion by the staff ED physician proved unsuccessful, and unfortunately (due to the holiday) no urologist was on-call at this facility. Consequently, the patient was transferred to a larger regional medical center with urologic coverage. Further examination demonstrated a swollen, tender, erythematous left hemi-scrotum without evidence of infection. Immediate surgical exploration confirmed $540^{\circ}$ testicular torsion and an ischemic, necrotic testicle (Fig. 1). The patient underwent a left orchiectomy followed by a right orchidopexy. Pathologic examination revealed hemorrhagic infarction of the left testicle (Fig. 2). The patient was discharged on Christmas Day without sequelae.

This case represents an atypical presentation of acute testicular torsion. Acute testicular torsion is rare in the

\section{B. Allen $(\square)$}

College of Medicine, Florida State University,

Fort Pierce Regional Campus 3209 Virginia Ave.,

Fort Pierce, FL 34981, USA

e-mail: bra07md@gmail.com

\section{A. J. Ball}

Clinical Faculty Member-Urology, Florida State University College of Medicine, Fort Pierce, USA

e-mail: adamballmd@hotmail.com

\section{A. Desai}

Lawnwood Regional Medical Center,

Fort Pierce, USA

e-mail: anilgdesai@gmail.com sixth decade of life and has only been cited in a case report on one prior occasion [1]. This appearance of torsion eclipses the classic bimodal distribution of peak incidence

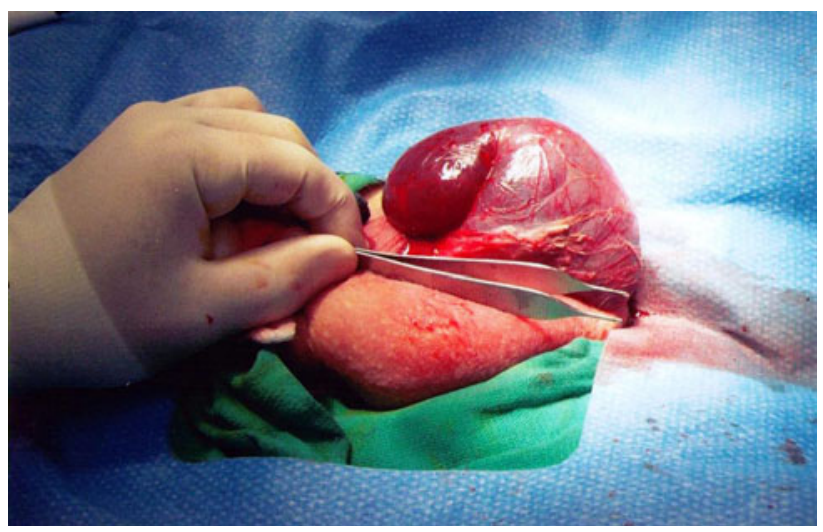

Fig. 1 Intraoperative image displaying ischemic, necrotic testicle following detorsion

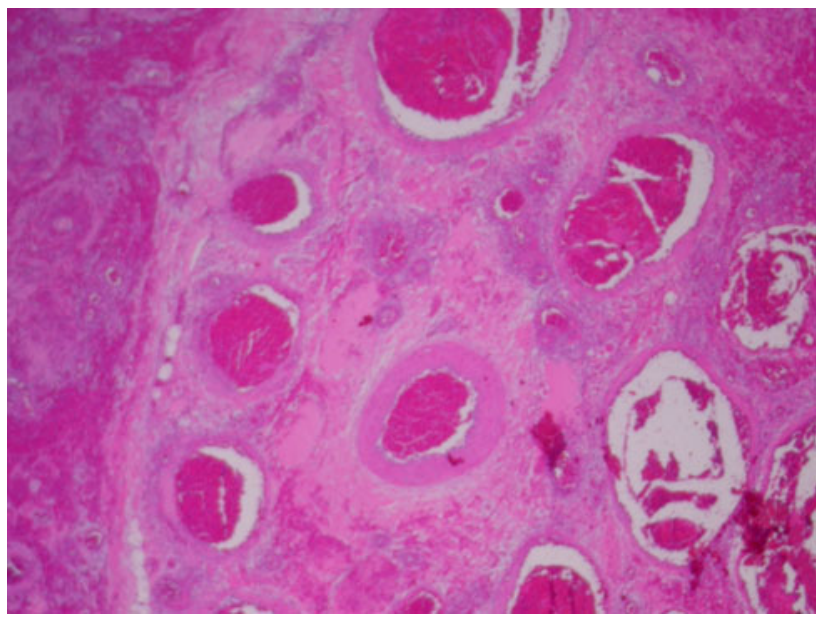

Fig. 2 Hemorrhagic necrosis of testicular tissue 
in infancy and adolescence. $85 \%$ of cases occur between ages 12 and 18 with a mean age of 13 years [2]. Nevertheless, this case reinforces that a high level of suspicion for torsion must remain no matter the age of your patient.

\section{Conflict of interest None.}

\section{References}

1. Ilbey YO, Ozbek E, Simşek A (2008) Torsion of testis with large epididymal cyst in a 57-year-old man: a case report. Arch Ital Urol Androl 80:111-112
2. Newton E (2007) Testicular torsion. Rosen \& Barkin's 5-minute emergency medicine consult, 3rd edn. Lippincott Williams \& Wilkins, Philadelphia 